Article

\title{
Influence of Naturally Occurring Simian Foamy Viruses (SFVs) on SIV Disease Progression in the Rhesus Macaque (Macaca mulatta) Model
}

Anil Choudhary ${ }^{1, \dagger, \dagger}$, Teresa A. Galvin ${ }^{1, \dagger}$, Dhanya K. Williams ${ }^{1, \dagger}$, Joel Beren ${ }^{2, \ddagger}$, Mark A. Bryant ${ }^{3}$ and Arifa S. Khan ${ }^{1, *}$

1 Laboratory of Retroviruses, Division of Viral Products, Center for Biologics Evaluation and Research, US Food and Drug Administration, Bethesda, MD 20892, USA;

E-Mails: anil.choudhary@fda.hhs.gov (A.C.); teresa.galvin@fda.hhs.gov (T.A.G.); dhanya.williams@fda.hhs.gov (D.K.W.)

2 Division of Veterinary Services, Center for Biologics Evaluation and Research, US Food and Drug Administration, Bethesda, MD 20892,USA; E-Mail: joel.beren@fda.hhs.gov

3 Division of Veterinary Resources, Office of Research Services, National Institutes of Health, Bethesda, MD 20892, USA; E-Mail: bryantm@ors.od.nih.gov

$\uparrow$ These authors contributed equally to the work.

* Current address: Office of Compliance and Biologics Quality, DBSQC, CBER, FDA, Kensington, MD 20895, USA (A.C.); Office of Medical Products and Tobacco, OCTEC, CDER, FDA, Silver Spring, MD 20993, USA (J.B.).

* Author to whom correspondence should be addressed; E-Mail: arifa.khan@fda.hhs.gov; Tel.: +1-301-827-0791; Fax: +1-301-496-1810.

Received: 25 April 2013; in revised form: 22 May 2013 / Accepted: 30 May 2013 / Published: 6 June 2013

\begin{abstract}
We have investigated the influence of naturally occurring simian foamy viruses (SFVs) on simian immunodeficiency virus (SIV) infection and disease in Indian rhesus macaques. Animals were divided into two groups based upon presence or absence of SFV; in each group, eight monkeys were injected with $\mathrm{SIV}_{\text {mac239 }}$ virus obtained from a molecular clone and four were injected with medium. Blood was collected every two weeks for evaluation of SIV infection based upon T cell-subsets, plasma viral load, development and persistence of virus-specific antibodies, and clinical changes by physical examination and hematology. Comparative analysis of $\mathrm{SFV}+/ \mathrm{SIV}+$ and $\mathrm{SFV}-/ \mathrm{SIV}+$ monkey groups
\end{abstract}


indicated statistically significant differences in the plasma viral load between 6-28 weeks, particularly after reaching plateau at 20-28 weeks, in the $\mathrm{CD} 4^{+}$and $\mathrm{CD} 8^{+} \mathrm{T}$-cell numbers over the entire study period (2-43 weeks), and in the survival rates evaluated at 49 weeks. There was an increase in the plasma viral load, a decreasing trend in the $\mathrm{CD} 4{ }^{+} \mathrm{T}$ cells, and a greater number of animal deaths in the SFV+/SIV+ group. The results, although based upon a small number of animals, indicated that pre-existing SFV infection can influence SIV infection and disease outcome in the rhesus macaque model. The study highlights consideration of the SFV status in evaluating results from SIV pathogenesis and vaccine challenge studies in monkeys and indicates the potential use of the SFV/SIV monkey model to study the dynamics of SFV and HIV-1 dual infections, recently reported in humans.

Keywords: Indian rhesus macaques; simian immunodeficiency virus; simian foamy virus; SIV pathogenesis; preclinical AIDS model; dual retrovirus infections

\section{Introduction}

Various simian immunodeficiency viruses (SIVs) and chimeric simian-human immunodeficiency viruses (SHIVs) have been used in different macaque species for studying AIDS pathogenesis and evaluation of vaccine efficacy [1]. A well-established model for investigating the correlates of protection and studying SIV infection and disease progression is $\mathrm{SIV}_{\text {mac239 }}$ infection in Indian rhesus macaques. A major challenge in the nonhuman primate (NHP) models has been variability of results, even when using the same inoculum. This may be due to various host factors including genetic, immunologic, microbiologic, and age-related, or to environmental factors such as housing and handling, which can induce stress or introduce exogenous viruses. An important virologic factor that is generally overlooked is the high prevalence $(75 \%-100 \%)$ of simian foamy viruses (SFVs) in nonhuman primates, which can become $90 \%-100 \%$ during captivity. SFV infection in monkeys is generally latent; although proviral DNA can be detected in all tissues, viral RNA expression is seen only in oral tissues [2,3]. Circulating SFVs have coevolved with their host species [4] and the virus genome diversity seen in naturally occurring viruses may have occurred due to intra-species or inter-species transmission [5].

SFV has a very broad host range and tissue tropism. Although SFV can result in a lytic infection in fibroblasts in tissue culture and a persistent infection in epithelial cells [6], there is no evidence of clinical signs in vivo in any animal species by natural or experimental infection [7,8]. SFV infections have also occurred in humans due to occupational exposure to infected NHPs or tissues or in natural settings [9-14] and can result in lifelong persistence of infectious virus [15]. In fact, SFV and HIV-1 coinfections have been reported in Africa [16]. Although there is no evidence of SFV-induced disease or human to human transmission, dual retrovirus infections may pose a concern based upon results from a retrospective study that showed expanded tissue targets of SFV expression were seen in SIV-immunosuppressed monkeys [17]. This concern is particularly relevant to SFV-infected populations in Southeast Asia and Central Africa, which are also high risk areas for HIV-1 infections. Furthermore, in vitro experiments and transgenic mouse studies have shown that prototype foamy virus (originally designated as human foamy virus) can increase HIV-1 gene expression [18,19] and 
cell binding [20]. Our study was designed to investigate the influence of naturally occurring SFV infections on SIV-induced AIDS in rhesus macaques and to evaluate the potential use of the SFV/SIV monkey model for investigating consequences of dual SFV and HIV-1 infections in humans.

\section{Results and Discussion}

\subsection{Study Design}

Dual SFV and SIV infection was investigated in the well-established SIV mac239-Indian rhesus macaque model [1]. Monkeys selected for this study were initially evaluated clinically for good health (body weight, $\mathrm{CBC}$ differential, and serum chemistry) and prescreened for simian viruses and other microbial agents. All animals were individually housed during this screening period and thereafter. Immunophenotyping was done to determine the number of $\mathrm{CD}^{+} \mathrm{T}$ cells, $\mathrm{CD} 8^{+} \mathrm{T}$ cells and $\mathrm{B}$ cells. MHC class I and class II genes that have been reported to influence SIV infection [21,22] were determined retrospectively. Additionally, to minimize variability in the results due to genetic diversity in the virus inoculum, $\mathrm{SIV}_{\text {mac239 }}$ virus stock was prepared from an infectious, cloned DNA [23] with minimum cell passage. The details are described in Section 3.1.

Although 24 animals were initially selected as SFV negative based upon serological screening of 70 animals, subsequent PCR analysis indicated that only 12 animals were SFV negative and 12 were SFV positive. The results are shown in Figure 1. Virus identity was confirmed by nucleotide sequence analysis of the PCR amplified fragments. The SFV status in the animals was confirmed at various time points prior to study initiation.

Figure 1. SFV status in monkeys by PCR analysis. Peripheral blood mononuclear cell (PBMC) DNA was isolated from 24 monkeys at 5 months prior to initiation of the study and analyzed by a nested PCR assay using SFV set B primers resulting in a $390 \mathrm{bp}$ fragment. PCR amplification of a $\sim 300$ bp Mamu-DRB gene fragment was used as a control to determine the presence of intact DNA in the test samples.

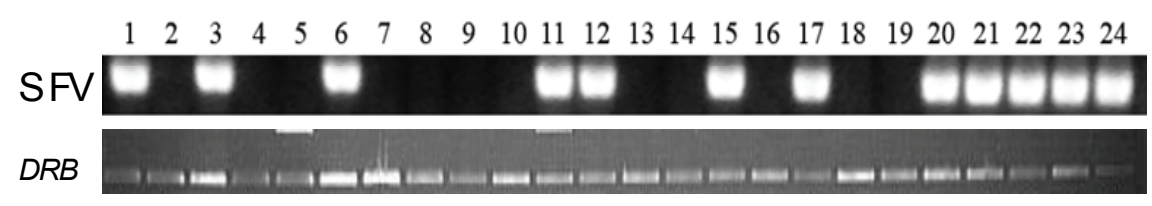

Based upon the SFV status of the animals, monkeys were divided into two groups consisting of $12 \mathrm{SFV}$-negative animals and $12 \mathrm{SFV}$-positive animals (designated as SFV- and SFV+, respectively): in each group, eight animals were injected with $\operatorname{SIV}_{\text {mac239 }}\left(1000 \mathrm{TCID}_{50}\right.$ or $12.33 \mathrm{ng}$ p27 antigen per $\mathrm{mL}$ per animal) and four were injected with medium as controls. Monkeys that were selected for SIV inoculation had good health and a normal range of $\mathrm{CD} 4^{+}$and $\mathrm{CD} 8^{+} \mathrm{T}$-cell counts.

\subsection{Evaluation of $T$ and $B$ cells}

$\mathrm{SIV}_{\text {mac239 }}$ infection in rhesus macaques results in decreasing $\mathrm{CD} 4^{+} \mathrm{T}$-cell numbers with disease progression, and quantitative and qualitative changes in the $\mathrm{CD} 8^{+} \mathrm{T}$ cells occur in response against the 
infection. Therefore, $\mathrm{CD} 4^{+}$and $\mathrm{CD} 8^{+} \mathrm{T}$ cells were monitored in this study to compare these parameters in SIV-infected, SFV negative and SFV positive monkeys. The absolute number of $\mathrm{T}$ cells was calculated using the percentage of $\mathrm{CD}^{+} \mathrm{T}$-lymphocyte subsets $\left(\mathrm{CD} 4^{+}, \mathrm{CD} 8^{+}\right.$cells) determined by flow cytometry, and the number of total lymphocytes was determined from the $\mathrm{CBC}$ analysis. The T-cell data for individual animals are shown in Figure 2. There was a decrease in the $\mathrm{CD} 4{ }^{+} \mathrm{T}$ cells through week 14 seen in all of the animals in the study including controls (data not shown), which may be age-related, followed by recovery in all animals, except those in the SFV+/SIV+ group. Furthermore, increases in the $\mathrm{CD}^{+} \mathrm{T}$ cells were seen in the SFV-/SIV+ monkeys after week 14 but not in the $\mathrm{SFV}+/ \mathrm{SIV}+$ animals.

Figure 2. Comparison of $\mathrm{CD} 4^{+}$and $\mathrm{CD} 8^{+} \mathrm{T}$ cells in SIV-infected monkeys. The numbers of $\mathrm{CD}^{+}{ }^{\mathrm{T}}$ cells and $\mathrm{CD} 8^{+} \mathrm{T}$ cells were determined for week 0 (prior to SIV injection) and after injection through week 43 for each monkey or earlier in case of termination due to disease (indicated in red with a symbol). Animals are grouped based upon SFV status for comparison and listed individually in each group.
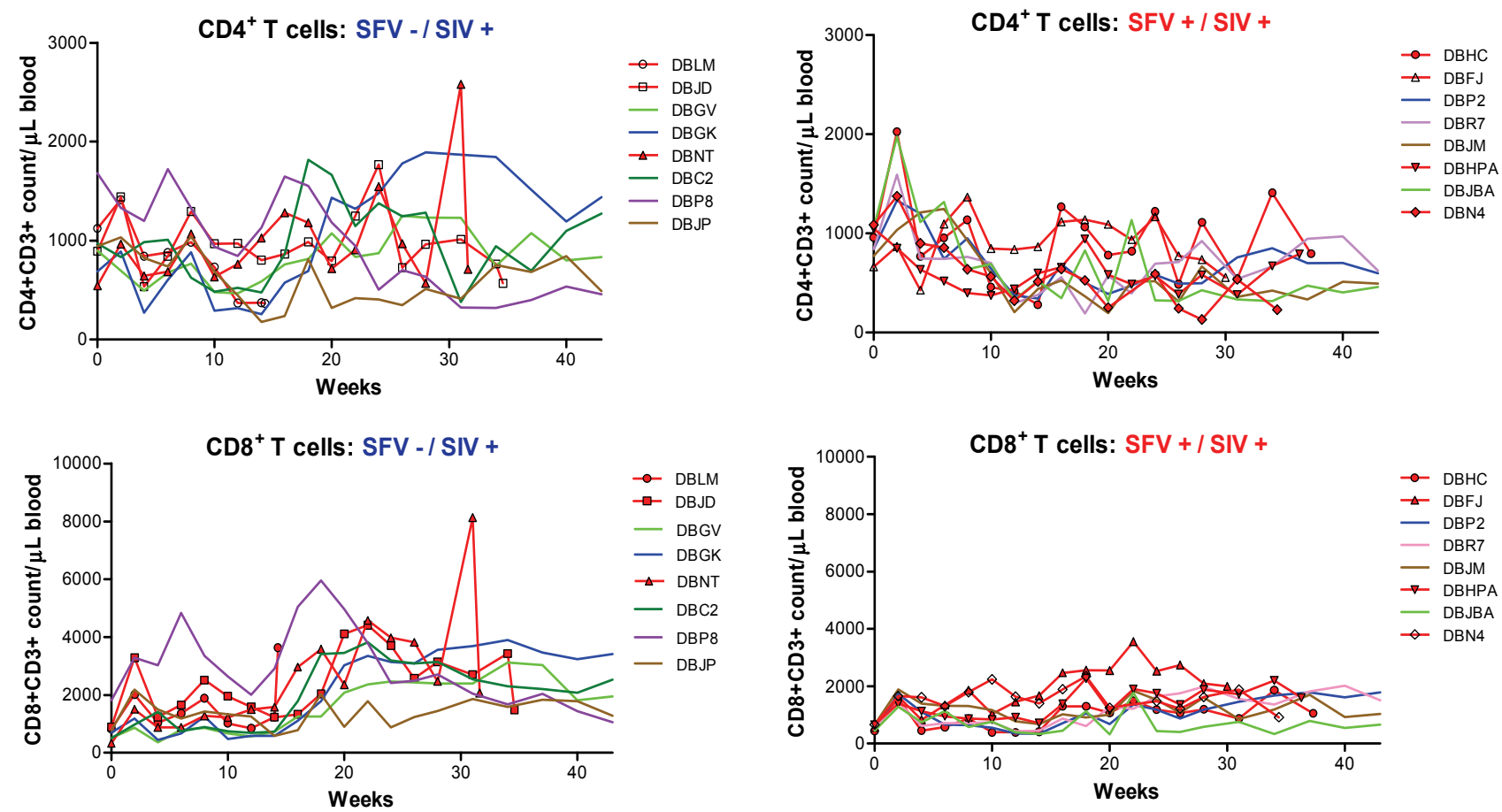

To further evaluate the changes in the T-cell subsets, the results were longitudinally evaluated based upon a linear regression analysis of all of the animals in each group ( 8 in each of the test groups: SFV-/SIV+, and SFV+/SIV+; 4 in each of the control groups: SFV-/SIV-, and SFV+/SIV-) by calculating the percent change in the number of cells in each animal at each time point, after normalizing to week 0 (Figure 3). The results showed a decreasing trend in the $\mathrm{CD}^{+}{ }^{+} \mathrm{T}$ cell number in the $\mathrm{SFV}+/ \mathrm{SIV}+$ animals as compared with the SFV-/SIV+ animals $(p=0.001)$. In contrast, a trend toward an increase in the $\mathrm{CD} 8^{+} \mathrm{T}$ cells was seen in these two animal groups; however, a lesser increase was seen in the SFV+/SIV+ animals as compared with the SFV-/SIV+ animals $(p=0.02051)$. Similar results were obtained when the data was re-analyzed without DBNT and DBGK, assuring that some of the elevated T-cell numbers associated with these two animals did not skew the trend analysis in the 
SFV-/SIV + group of animals. An increasing trend was seen in the CD20 $0^{+}$B cells in the SIV-infected animals, but the difference between the SFV positive and SFV negative groups was not statistically significant $(p=0.1)$. Furthermore, there was no statistical difference in the T-cell subsets or B cells between the SFV positive and SFV negative animals in the control SIV negative group. These results indicated that SFV may influence T-cell subsets in SIV-infected macaques.

Figure 3. Longitudinal analysis of $\mathrm{T}$ and $\mathrm{B}$ cells. Linear regression (GraphPad Prism, v5.0, La Jolla, CA, USA) of percent changes in T and B cells in SFV positive and SFV negative monkey groups was done by calculating the percent change in cells as compared to week 0 for each animal at each time point. $\mathrm{CD} 4^{+}$and $\mathrm{CD} 8^{+} \mathrm{T}$ cell counts and $\mathrm{CD} 20^{+} \mathrm{B}$ cell counts were determined by flow cytometry using freshly collected blood in EDTA anticoagulant. The groups of SIV positive and control SIV negative monkeys are shown. Mean \pm SD was determined based upon the percent change in cells for all of the monkeys at each time point per group. The difference in the slope of the linear regression curve with regard to week 0 is indicated by the boxed $p$ values. The statistically significant $p$ values between the monkey groups are indicated by an arrow $(<0.1)$.

\section{SIV+}

\section{SIV-}

\section{$\mathrm{CD}^{+} \mathrm{T}$ cells}
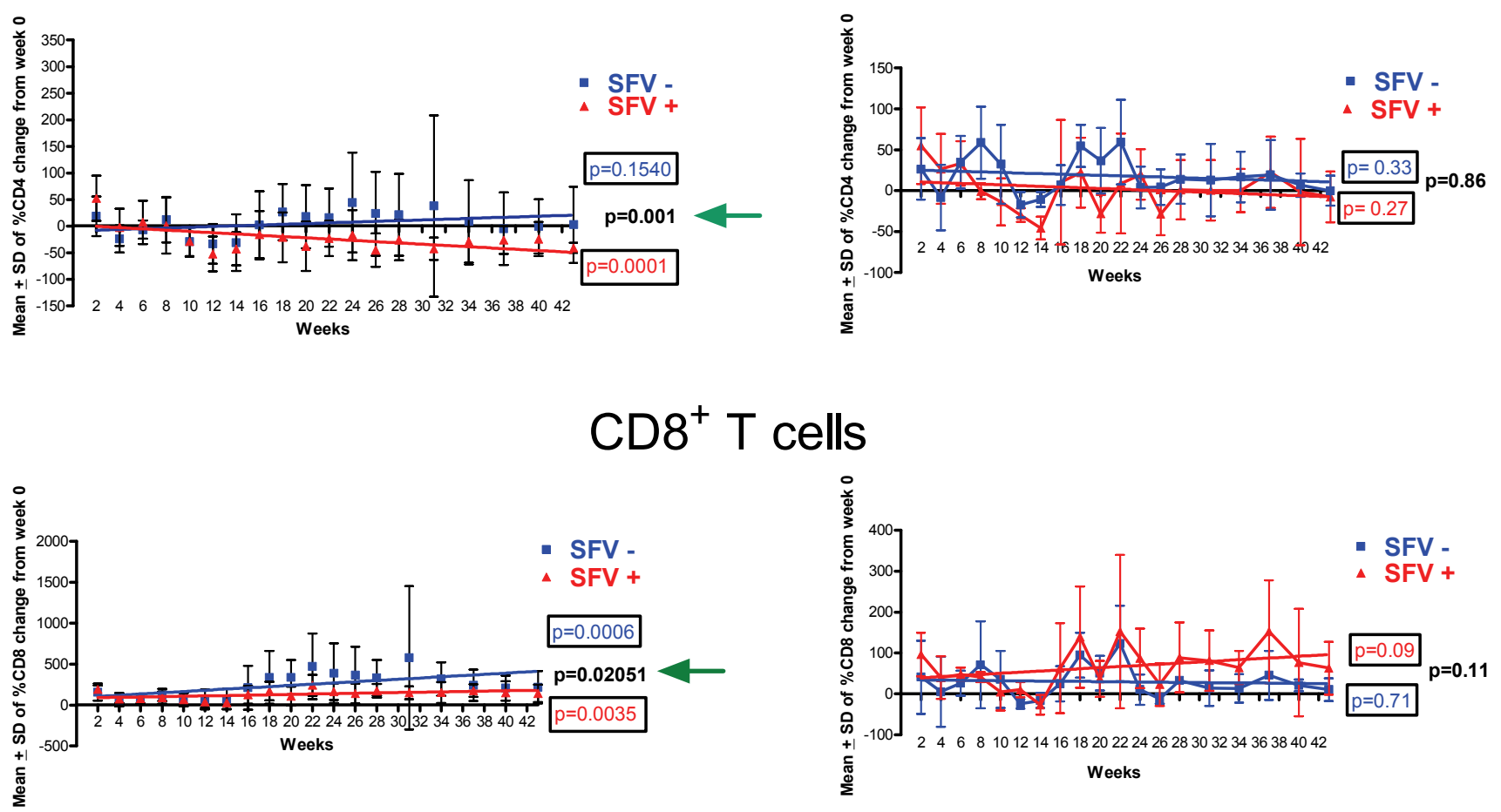
Figure 3. Cont.

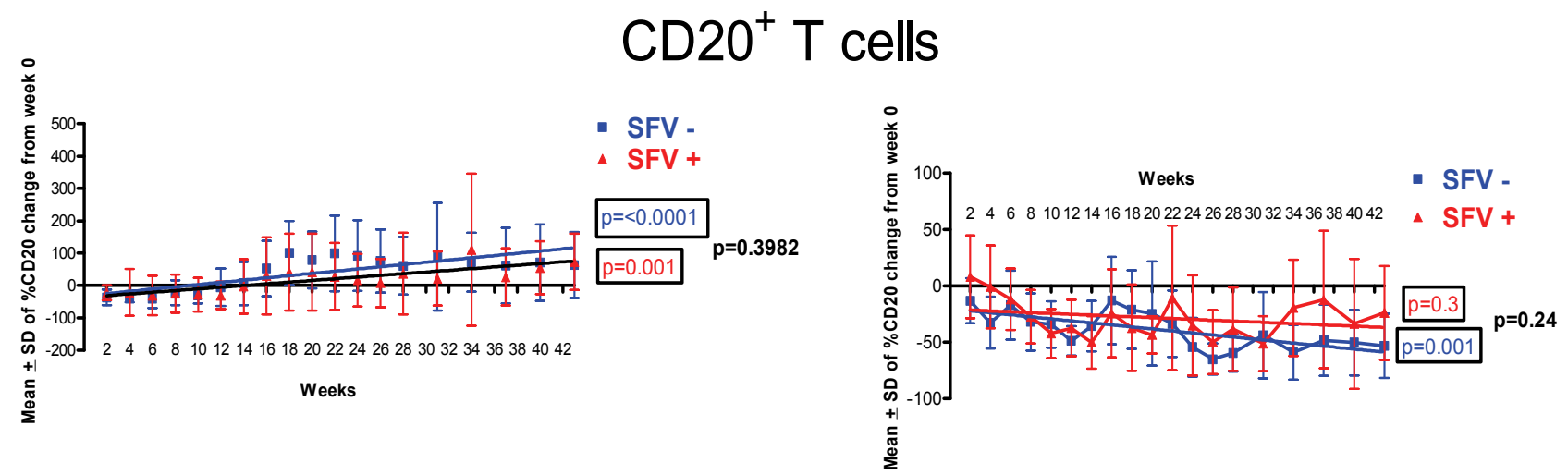

\subsection{Plasma Viral Load Analysis in SIV-infected Monkeys}

SIV viral RNA load was evaluated by bDNA analysis. The results (Figure 4) indicated an early acute phase and the viral load reached a plateau at about week 20. SIV viral loads were similar to those reported in previous studies [24]. The SFV negative and SFV positive groups had similar viral loads up to week 4, after which the viral load in the SFV positive group was slightly elevated compared with the SFV negative group. A statistically higher viral load was seen in the SFV positive group compared with the SFV negative group between weeks 6-28 $(p=0.0055)$; this was more pronounced at weeks 20-28 $(p<0.0001)$ (Figure 4). The results indicated that pre-existing SFV infection correlated with a higher viral load in SIV-infected monkeys that was maintained over the study period.

Figure 4. SIV viral load analysis. Plasma viral load was determined at the indicated times by bDNA from weeks 2 through 34 . Mean \pm SEM of the results from SFV $+/ \mathrm{SIV}+$ and $\mathrm{SFV}-/ \mathrm{SIV}+$ monkey groups was plotted 2-34 weeks. Box and whiskers analysis of the plasma viral load from 6-28 weeks and 20-28 weeks for the SFV positive and SFV negative monkey groups is shown; $p$ values and number of animals in each group are indicated.
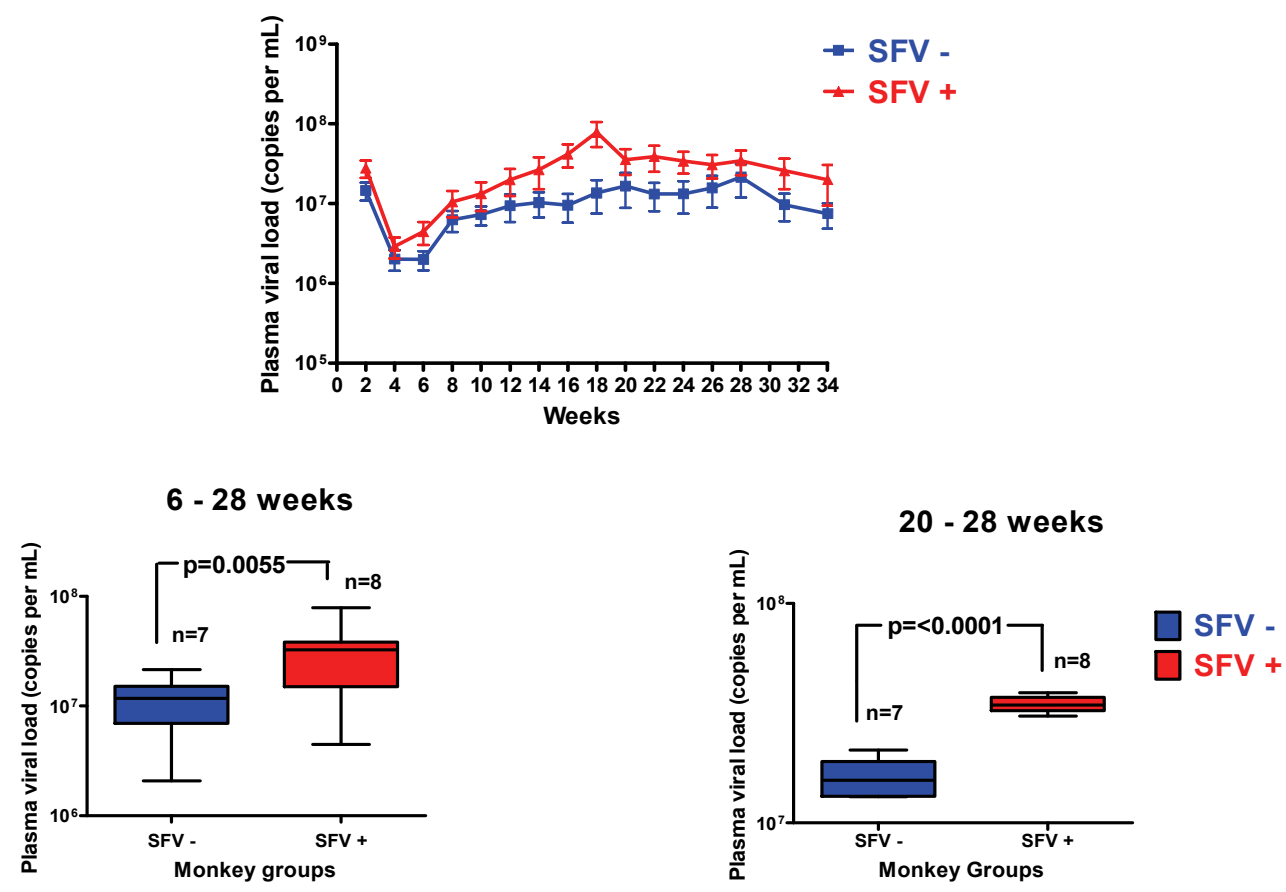


\subsection{Survival Analysis and Disease Progression}

The influence of SFV infection on SIV clinical outcome was examined by plotting survival curves of the different animal groups. The results (Figure 5) showed 100\% survival in the control SIV negative group (which included both SFV negative and SFV positive animals) and about $63 \%$ survival in the SFV-/SIV+ group at 49 weeks; however, only $25 \%$ survival was seen in the SFV+/SIV+ group. The log-rank (Mantel-Cox) test indicated that there was a significant difference in the survival curves ( $p=0.0217)$ at 49 weeks; a negative impact was seen in the presence of SFV on survival of the SIV-infected animals. Animals were euthanized from 30 to 133 weeks after SIV injection upon development of severe AIDS related symptoms, such as significant weight loss (about 20\%), loss of appetite, chronic diarrhea, and pneumonia, except in one case (DBGV). Review of the pathological reports following necropsy showed that all SIV-injected monkeys died due to SIV-related disease, except for DBGV, which was terminated at the end of the study and exhibited no severe symptoms at the time of death.

Figure 5. Monkey survival curves. The Log-rank (Mantel-Cox) test indicated the difference in the survival curves as $p=0.0217$ at 49 weeks after injection.

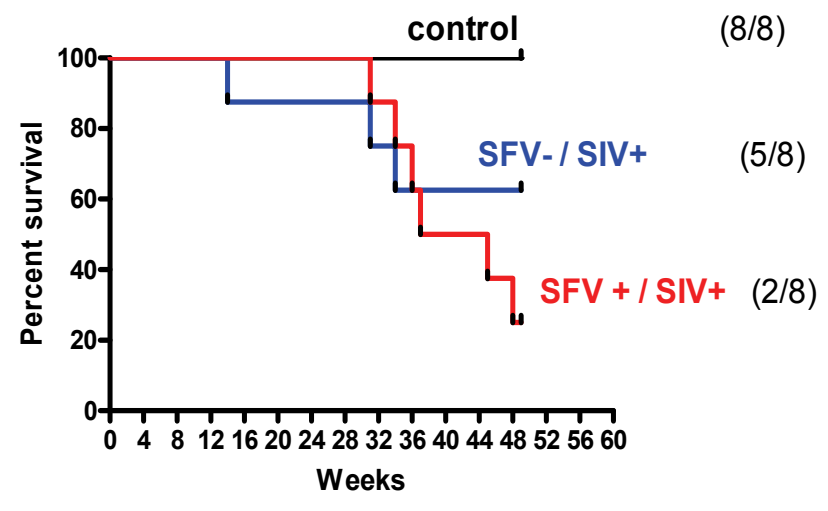

The study animals were further grouped based upon the rate of SIV disease progression and SFV status (Table 1). The results showed that one animal that was a rapid progressor (DBLM) was SFV negative, 10 were conventional progressors, of which 3 were SFV negative, and 5 were slow progressors of which 4 were SFV negative. Additionally, the development of p27 Gag antibodies was evaluated at various time points throughout the study period (Figure 6A). A loss of Gag antibodies was seen in some of the animals as expected with development of end-stage AIDS. Furthermore, Env gp120 binding antibodies (Figure $6 \mathrm{~B}$ ) and $\mathrm{SIV}_{\text {mac239 }}$ neutralizing antibodies were evaluated from weeks $0-49$ in animals that maintained Gag antibody. Neutralization $\left(\mathrm{ID}_{50}\right)$ was determined in the TZM-bl assay using SIVmac239Cs.23 [25]. The results at week 37 indicated four animals were positive based upon a cut-off value $>1: 40$ (due to assay background at 1:20), which represented the sample dilution at which relative luminescence units (RLUs) were reduced 50\% compared to virus control wells (no test sample). These were: DBR7, 1:75; DBJP, 1:179; DBGV, 1:41; and DBP2, 1:518. The results indicated that all the animals were positive for Gag antibodies at 4-6 weeks after SIV injection, and in most cases, thereafter until study termination. In general, there seemed to be higher Gag antibody responses in the SFV positive monkeys, but there were outliers in each group, so no 
direct correlation could be made between the SFV status, disease progression, and antibodies against SIV based upon the current data (Table 1).

Table 1. SIV groups based upon disease progression. Monkeys were grouped based upon rapid, conventional, or slow disease progression. The SFV status and the gp120 ELISA OD are also indicated.

\begin{tabular}{|c|c|c|c|c|c|}
\hline \multirow{2}{*}{$\begin{array}{c}\text { Monkey } \\
\text { ID }\end{array}$} & \multirow[t]{2}{*}{ SFV status } & \multicolumn{3}{|c|}{$\begin{array}{c}\text { Disease progression } \\
\text { (termination week) }\end{array}$} & \multirow[t]{2}{*}{$\begin{array}{l}\text { Gp120 ELISA OD } \\
\text { (week } 4 \text { and week } 37 \text { or } \\
\text { earlier terminal week) }\end{array}$} \\
\hline & & $\begin{array}{c}\text { Rapid } \\
(<6 \text { month })\end{array}$ & $\begin{array}{l}\text { Conventional } \\
\text { (6-24 month) }\end{array}$ & $\begin{array}{c}\text { Slow } \\
\text { (>2 year) }\end{array}$ & \\
\hline DBLM & - & 14 & & & $0.270 / 1.962$ \\
\hline DBFJ & + & & 30 & & $\mathrm{NT}^{\mathbf{b}}$ \\
\hline DBNT & - & & 31 & & $\mathrm{NT}^{\mathbf{b}}$ \\
\hline DBJD & - & & 34 & & $\mathrm{NT}^{\mathbf{b}}$ \\
\hline DBN4 & + & & 34 & & $0.158 / 0.835$ \\
\hline DBHPA & + & & 36 & & $\mathrm{NT}^{\mathbf{b}}$ \\
\hline DBHC & + & & 36 & & $\mathrm{NT}^{\mathbf{b}}$ \\
\hline DBR7 & + & & 45 & & $0.235 / 1.294$ \\
\hline DBJM & + & & 48 & & $0.465 / 1.983$ \\
\hline DBJBA & + & & 83 & & $0.646 / 2.367$ \\
\hline DBJP & - & & 83 & & $0.356 / 1.475$ \\
\hline DBP8 & - & & & 115 & $0.167 / 1.049$ \\
\hline DBGK & - & & & 124 & $0.222 / 1.136$ \\
\hline DBC2 & - & & & 133 & $0.181 / 0.706$ \\
\hline $\mathrm{DBGV}^{\mathrm{c}}$ & - & & & 141 & $0.159 / 2.082$ \\
\hline DBP2 & + & & & 128 & $0.658 / 0.864$ \\
\hline
\end{tabular}

\subsection{MHC Alleles}

Certain Macaca mulatta (Mamu) MHC class I alleles have been associated with protection against SIV infection in Indian rhesus macaques [26]. Animals positive for $M a m u-A 1 * 01, M a m u-B * 08$, and Maтu- $B^{*} 17$ tend to show lower set point plasma viral loads in SIV infection resulting in slower disease progression [27-30] (indicated in red in Table 2). Mamu- $B^{*} 17$, and Mamu- ${ }^{*} 08$ have been correlated with spontaneous SIV control; Мamu- $A^{*} 01^{+}$monkeys are long-term nonprogressors (LTNP) and $M a m u-A^{*} 02^{+}$monkeys are intermediate progressors with moderate resistance to SIV infection. Other alleles such as Mamu-A1*02, Maтu-A1*08, Maти-A1*011, Мати-B*01, Mamu- $B^{*} 03$, and $M a m u-B * 04$ have been implicated in the restriction of SIV or SHIV CD8 ${ }^{+}$T-cell epitopes. Additionally, Mamu- $A^{*} 07$ may have a potential role in the immune response against SIV [31]. MHC class II alleles Mamu-DRB1*0306 and Mamu-DRB1*1003 have been shown to be highly expressed in elite controllers and to contribute to reducing SIV viral load along with Mamu- $B^{*} 17$-positive animals [21]. To determine if the MHC class I and class II alleles previously 
studied in SIV infection were involved in the increased in the number of deaths seen in our study in the $\mathrm{SFV}+$ monkeys as compared to the SFV- monkeys, monkey DNAs were submitted for a retrospective study using allele-specific PCR assays [22]. The results are shown in Table 2. It should be noted that the one $\mathrm{SFV}^{+} \mathrm{SIV}^{+}$monkey that was a slow progressor (DBP2) had both SIV-controlling alleles Mamu- $B^{* 08}$ and $M a m u-B * 17$ and also had Mamu-DRB1*1003. However, there was no other correlation noted with disease progression and the presence of any of the other alleles tested in this study. All were negative for Mamu-A1*011, Мamu-A1*07, Мamu-B*03, Mamu-B*04, DRB $1 * 0306$.

Figure 6. Evaluation of SIV Gag and Env antibodies. (A) Plasma samples from week 6 and week 12 were analyzed for Gag antibodies by Western blot assays using p27 antigen. (B) Animals that were positive for anti-gp120 antibodies in a Western blot assay using SIV-infected cell lysate were further analyzed by ELISA using 1:100 dilution of plasma and SIV $_{\text {mac239 }}$ gp120 antigen. The mean \pm SEM of animals in the SFV positive group and SFV negative group is shown for selected time points. The number of animals at each time point in the case of the SFV positive group were: five for week 0, 4, 12, and 16 (DBP2, DBR7, DBJM, DBJBA, and DBN4), four for week 8 (no sample was available from DBR7) and 37 (DBN4 died at week 34); and the number of animals in the SFV- group were: six for week 0, 4, 8, and 12 (DBLM, DBGV, DBGK, DBC2, DBP8, and DBJP), and five for week 16 and 37 (DBLM died at week 14). Data for week 4 and week 37 or terminal time point is shown in Table 1.

(A)

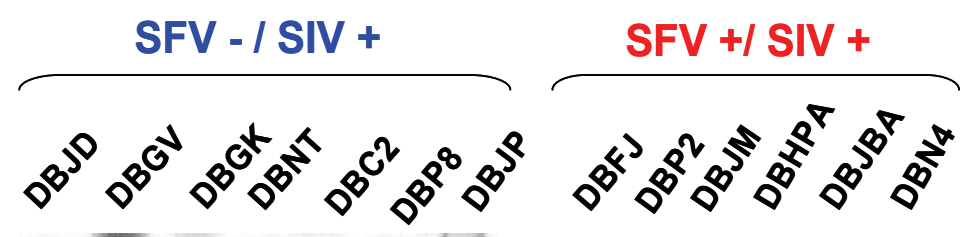

week 6

week 12

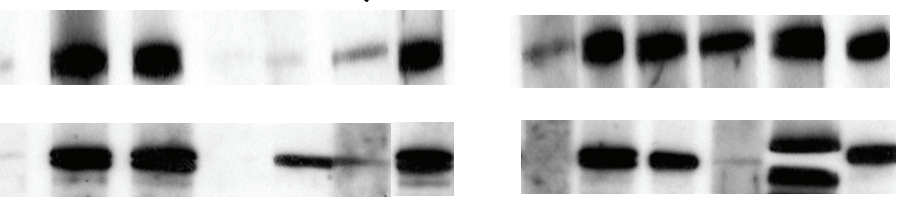

(B)

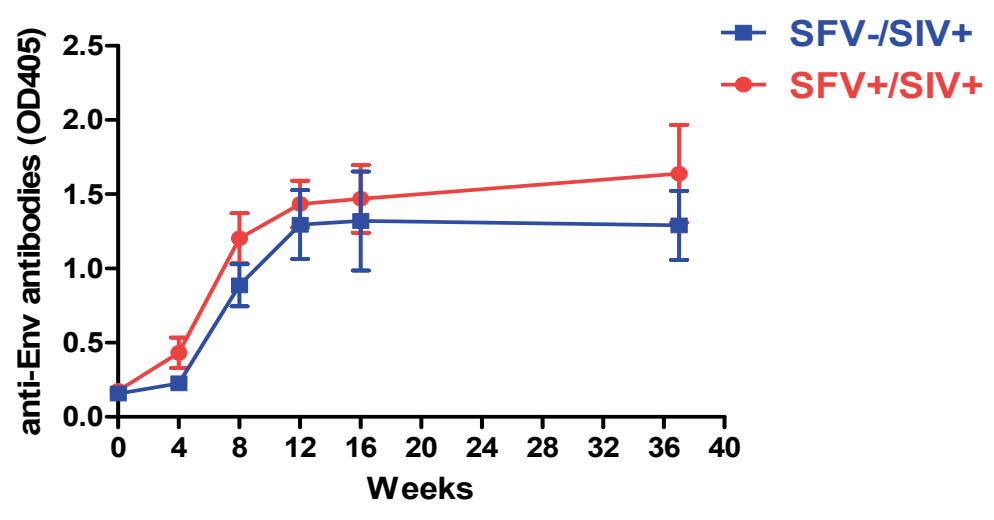


Table 2. MHC genotyping of SIV-infected monkeys a .

\begin{tabular}{|c|c|c|c|c|c|}
\hline \multirow{2}{*}{$\begin{array}{l}\text { Monkey } \\
\text { ID } \\
\end{array}$} & \multirow{2}{*}{$\begin{array}{c}\text { SFV status/ } \\
\text { Monkey survival (weeks) } \\
\end{array}$} & \multicolumn{2}{|c|}{ Class I $^{b}$} & \multicolumn{2}{|c|}{ Class II $^{\text {b }}$} \\
\hline & & Мати-A & Мати-B & Mamu-DR & Mamu-DP \\
\hline & & $A * 01^{c}$ & $B * 01$ & $B 1 * 0306, B 1 * 1003$ & \\
\hline & & $A * 02$ & $B * 08$ & $B * w 201, B * w 606$ & $B 1 * 06$ \\
\hline & & $A * 08$ & $B * 17$ & $B 1 * 04$ & \\
\hline DBLM & $-/ 14$ & $A * 02$ & & $B * w 201, B * w 606$ & \\
\hline \multirow{2}{*}{ DBFJ } & \multirow{2}{*}{$+/ 30$} & \multirow{2}{*}{$A * 02$} & \multirow{2}{*}{\multicolumn{3}{|c|}{$\begin{array}{c}B 1 * 0306, B 1 * 1003 \\
B * w 606\end{array}$}} \\
\hline & & & & & \\
\hline \multirow{2}{*}{ DBNT } & \multirow{2}{*}{$-/ 31$} & $A * 01$ & \multirow{2}{*}{$B * 01$} & $B 1 * 1003$ & \\
\hline & & $A * 08$ & & $B *_{w 201, B} *_{w 606}$ & \\
\hline \multirow{2}{*}{ DBJD } & \multirow{2}{*}{-134} & $A * 02$ & & $B * w 201$ & \\
\hline & & $A * 08$ & & $B 1 * 04$ & \\
\hline \multirow{2}{*}{ DBN4 } & \multirow{2}{*}{$+/ 34$} & & \multirow{2}{*}{$B * 01$} & $B 1 * 1003$ & \\
\hline & & & & $B 1 * 04$ & $B 1 \times 0$ \\
\hline DBHPA & $+/ 36$ & $A^{*} 02$ & $B * 01$ & $B 1 * 1003$ & \\
\hline \multirow{3}{*}{ DBHC } & \multirow{3}{*}{$+/ 36$} & & \multirow{3}{*}{$B * 01$} & $B 1 * 1003$ & \\
\hline & & & & $B * w 201$ & \\
\hline & & & & $B 1 * 04$ & \\
\hline \multirow{2}{*}{ DBR7 } & \multirow{2}{*}{$+/ 45$} & & & $B 1 * 0306$ & \\
\hline & & & & $B 1 * 1003$ & \\
\hline \multirow{2}{*}{ DBJM } & \multirow{2}{*}{$+/ 48$} & \multirow{2}{*}{$A * 02$} & & $B * w 606$ & \\
\hline & & & & $B 1 * 04$ & \\
\hline DBJBA & $+/ 83$ & $A * 08$ & & $B 1 * 1003$ & \\
\hline DBJP & $-/ 83$ & & & $B 1 * 1003$ & \\
\hline DBP8 & $-/ 115$ & $A * 02$ & & $B * w 201, B * w 606$ & \\
\hline \multirow{3}{*}{ DBGK } & \multirow{3}{*}{$-/ 124$} & \multirow{3}{*}{$A * 01$} & \multirow{3}{*}{$B * 01$} & $B 1 * 0306$ & \\
\hline & & & & $B 1 * 1003$ & \\
\hline & & & & $B * w 201$ & \\
\hline \multirow{2}{*}{$\mathrm{DBC} 2$} & $-/ 133$ & $A * 02$ & & $B 1 * 1003$ & \\
\hline & -1133 & $A=2$ & & $B * w 201, B * w 606$ & \\
\hline DBGV & $-/ 141$ & $A^{*} 02$ & & $B * w 201, B * w 606$ & \\
\hline & & $A * 08$ & & & \\
\hline DBP2 & $+/ 128$ & & $B * 08$ & $B 1 * 1003$ & \\
\hline DBP2 & $+/ 128$ & & $B * 17$ & $B * w 201$ & \\
\hline
\end{tabular}

a All were negative for $M a m u-A * 07, M a m u-B * 03$ and $M a m u-B * 04 ;{ }^{\mathrm{b}}$ Common allele names are used;

${ }^{\mathrm{c}}$ Protective alleles are indicated in red.

\section{Experimental}

\subsection{Animals, Prescreening for Selection, and Management}

Indian rhesus monkeys (Macaca mulatta) were obtained from a domestic breeding colony in Morgan Island, South Carolina (Alpha Genesis Inc., Yemassee, SC, USA). Monkeys (males; 1.5-2 years old) were initially selected based upon good physical health (with normal body weights between 2-3 kg and no signs of clinical problems) and negative serology for simian pathogens (measles virus, 
herpes B virus, simian type D retrovirus [SRV], simian T-lymphotropic virus [STLV], and SIV; VRL Laboratories, San Antonio, TX, USA). Additionally, the animals were pre-screened for SFV using a dot blot immunoassay [32] (VRL Laboratories). Animals were de-wormed for potential parasites using ivermectin, droncit, and fenbendazole treatment for 3 days.

Animals were individually maintained during the pre-screening period, shipping to FDA facilities (National Institutes of Health, Bethesda, MD, USA), and thereafter until the end of the study period. Animals care was in accordance with the Guide for the Care and Use of Laboratory Animals [33] under a protocol approved by the Institutional Animal Care and Use Committee (CBER, FDA). The animals were quarantined for 10-weeks upon arriving at the FDA nonhuman primate facilities $(\mathrm{NIH}$, Bethesda, MD, USA): after the initial 2-week acclimation period, animals received complete physical examinations, five intradermal tuberculin tests to assure absence of any Mycobacteria. Fecal cultures for bacteriology and parisitology were obtained. Some animals were de-wormed again. Additionally, each animal was tested to confirm their negative status for measles virus, herpes B virus, SIV, STLV and SRV by serology. The SRV status was verified by a virus-specific PCR assay (Pathogen Detection Laboratory, California National Primate Research Center, University of California Davis, Davis, CA, USA). Additionally, the SFV-seronegative status was evaluated in our laboratory by PCR analysis using Set B primers, which can detect naturally-occurring SFVs in rhesus and pig-tailed macaques [34]. DNA was prepared from monkey PBMCs (Qiagen DNA Blood Mini Kit, Valencia, CA, USA). Primers targeting the highly conserved region of the Mamu-DRB exon 2 (designated as 5'-MDRB and 3'-MDRB) were used as control [35]. Based upon the results, two study groups were formed containing 12 SFV positive and 12 SFV negative animals: each group contained 8 test animals and 4 control animals. At 8-weeks prior to initiation of the study, the SFV status of the animals was confirmed by PCR and all of the animals received routine measles virus vaccine subcutaneously (0.5 mL; Attenuvax, Merck). After an additional 4 week transient immunosuppression period due to the measles vaccine virus, the SFV status was again verified by PCR assay prior to study initiation.

The clinical health of the animals was evaluated by hematology and serum chemistry (Antech, Lake Success, NY, USA); animals with CBC values in the normal range were used as test animals. Monkey peripheral blood was additionally evaluated for $\mathrm{T}$-cell and B-cell numbers by immunophenotyping T-cell subsets $\left(\mathrm{CD}^{+}, \mathrm{CD}^{+}\right.$and $\mathrm{CD} 8^{+} \mathrm{T}$ cells) and $\mathrm{CD} 20^{+} \mathrm{B}$ cells (as described below); monkeys with similar cell counts were included in the study as test animals in an effort to minimize variability in the results subsequent to SIV infection.

In a retrospective analysis, DNA prepared from whole blood (Qiagen DNA Blood Mini Kit) was submitted for MHC class I and class II typing using rhesus sequence-specific priming (PCR-SSP) [22] (University of Wisconsin AIDS Vaccine Research Laboratory, Madison, WI, USA). Class I alleles included: $M a m u-A 1^{*} 01,-A 1^{*} 02,-A 1^{*} 08,-A 1^{*} 07$ and $-A 1^{*} 11$ (new nomenclature and allele specificity: Mamu-A1*001:01/001:02/001:03/001:04/001:05, $-A 1 * 002: 01, \quad-A 1 * 008: 01$ and $-A 1 * 011: 01$, respectively) and $M a m u-B * 01,-B^{*} 03,-B^{*} 04,-B^{*} 08,-B^{*} 17$ (new designations and allele specificity: Mamu- $B^{*} 001: 01: 01 / 001: 01: 02,-B^{*} 003: 01 / 066: 01,-B^{*} 004: 01 / 105: 01 / 106: 01,-B^{*} 008: 01$ and Mamu-B017:01/017:03. Class II alleles include: $D R B^{*} w 201, D R B * w 606, D R B 1 * 1003, D R B 1 * 04$, $D R B 1 * 0306$, and $D P B 1 * 06$ (new nomenclature and allele specificty: Mamu-DRB*w201, $-D R B * w 606$, -DRB1*03:01-03:08/03:10-03:18, -DRB1*04:01/06/11, -DRB1*10:03/06/08, and Mamu-DPB1*07:01, respectively). 


\subsection{Preparation and Characterization of SIV Inoculum}

Full-length, infectious $\mathrm{SIV}_{\text {mac239 }} \mathrm{SpX}$ cloned DNA [23] (kindly provided by R. Desrosiers; NIH AIDS Reagent Program, catalog number 12249) was transformed into E. coli Stbl2 cells (Invitrogen) and a large scale preparation was grown in LB broth containing $25 \mathrm{mg}$ per $\mathrm{L}$ ampicillin at $30{ }^{\circ} \mathrm{C}$, and DNA purified using Qiagen Maxi kit. The full-length of the DNA was confirmed by restriction enzyme digestion (BglII, HindIII and XhoI). $\mathrm{SIV}_{\text {mac239 }}$ virus stock was prepared as previously described [36]. 293T/17 cells (ATCC, Herndon, VA, USA) were transfected at 20\%-25\% confluence with $\mathrm{SIV}_{\text {mac239 }} \mathrm{SpX}$ cloned DNA (5 $\mu \mathrm{g}$ per $75 \mathrm{~cm}^{2}$ flask) using Profection Calcium Phosphate Transfection Kit (Promega, Madison, WI, USA). Supernatant was collected at $72 \mathrm{~h}$ post transfection and clarified by low speed centrifugation to remove whole cells.

The virus stock was characterized based upon its replication kinetics and by determining the total p27 antigen content, viral RNA copy number, and infectious titer. The total p27 antigen content was $685 \mathrm{ng} / \mathrm{mL}$ as determined by analyzing serial dilutions of the sample (1:128 to 1:512) according to the manufacturer's protocol in a SIV mac251 p27 antigen ELISA kit (Advanced BioScience Laboratories, Rockville, MD, USA). The infectious titer was determined as $10^{4.83} \mathrm{TCID}_{50}$ per $\mathrm{mL}$ [37] based upon inoculating serial 10-fold dilutions in 174×CEM cells [38] (NIH AIDS Research and Reference Reagent Program, NIH, Bethesda, MD; catalogue number 272) and determining p27 in the supernatant on day 7. Additionally, plasma SIV RNA was determined as $10^{8.9}$ copies per mL by a branched DNA (bDNA) signal amplification assay [39,40] (Siemens). The kinetics of $\mathrm{SIV}_{\text {mac239 }}$ replication were evaluated in $174 \times \mathrm{CEM}$ cells based upon p27 antigen in the supernatant at days $3,7,10$, and 13, collected just prior to splitting the cells. The kinetics of virus replication were as expected and a virus peak was seen on day 7 [41].

\subsection{Animal Injections, Blood Collections, and Necropsies}

Prior to SIV injection, control samples of blood were collected at various times in both EDTA and heparin anticoagulants for preparation of plasma and PBMCs to use in various assays for evaluation of SIV infection after monkey injection. At the time of virus injection (designated as week 0 ) and after injection (generally every two weeks), blood was collected in EDTA tubes for CBC differential and immunophenotyping; in EDTA PPT tubes for plasma separation for bDNA analysis (Becton, Dickinson and Company, Franklin Lakes, NJ, USA; catalogue number 362788); and in heparin CPT tubes (BD, catalogue number 362753) for PBMC preparation and plasma collection for ELISA and western blot analysis. Additionally, animals underwent a routine physical examination at time of each bleed. Blood was collected under sedation using ketamine hydrochloride $(10 \mathrm{mg} / \mathrm{kg})$. Animals were necropsied after development of severe AIDS-related symptoms (except in case of DBGV, a slow progressor that was necropsied at termination of the study) and tissues were collected for evaluation.

$\mathrm{SIV}_{\text {mac239 }}$ inoculum (1000 $\mathrm{TCID}_{50}$ or $12.33 \mathrm{ng}$ p27 antigen per $\mathrm{mL}$ per animal) was prepared by diluting the original stock in RPMI medium without added serum or other supplements (Quality Biologicals, Gaithersburg, MD, USA). Control animals received $1 \mathrm{~mL}$ medium. 


\subsection{Flow Cytometry}

EDTA-blood was pre-washed with room temperature cell-washing buffer (Dulbecco's PBS, without $\mathrm{Ca}^{++}$or $\mathrm{Mg}^{++}$; Quality Biologicals), and the original volume was reconstituted with the same buffer. Antibodies (10 $\mu \mathrm{L}$ each; FITC anti-CD3 epsilon, anti-CD4-PE, anti-CD8-PerCP and anti-CD20-FITC, catalogue number 556611, 550630, 347314 and 347673, respectively; BD Biosciences, San Jose, CA, USA) were added to $100 \mu \mathrm{L}$ aliquots of washed blood and incubated for $1 \mathrm{~h}$ at room temperature. Red blood cells were then lysed using BD FACS Lysing Solution (BD Biosciences, San Jose, CA, USA) according to the manufacturer's instructions. Cells were pelleted and washed three times in cell-washing buffer and fixed overnight at $4{ }^{\circ} \mathrm{C}$ in $250 \mu \mathrm{L}$ of $2 \%$ paraformaldehyde (EM-grade from Electron Microscopy Sciences). For flow cytometry analysis, ten thousand events were acquired in the lymphocyte region using Cell Quest (v3.1) on a FACSCalibur (Becton Dickinson). Data were analyzed using FlowJo software (v6.1.1; Treestar, Ashland, OR, USA).

\subsection{Plasma Viral Load}

EDTA plasma was evaluated for SIV RNA by a bDNA assay (Siemens, CA, USA). Plasma was aliquoted into single-use vials to avoid freeze thaw of samples. Bayer Reference Testing Laboratory performed viral quantitation of SIV in plasma samples using the Versant branched DNA (bDNA) method. RNA was extracted from $0.5 \mathrm{~mL}$ of monkey plasma and combined with probes targeting the pol region of SIV to allow for hybridization and binding to the microwell. The probe signal was then amplified to allow for detection of the target SIV RNA. The level of viral RNA in the test sample is quantified by comparing generated signals to a standard curve made using in vitro transcribed $\mathrm{SIV}_{\text {mac239 }}$ pol RNA. The results were reported in copies per $\mathrm{mL}$.

\subsection{Antibody Detection}

Anti-SIV antibodies were estimated in plasma collected in heparin from monkeys injected with $\mathrm{SIV}_{\text {mac239. }}$. Western blots were used to screen for the presence of antibodies in plasma over the period of the entire study. For performing western blots, purified SIV $_{\text {mac251 }}$ p27 (Advanced Bioscience Laboratories, MD, USA, catalogue number 4530) was run on 10\% SDS-PAGE for $1.5 \mathrm{~h}$ at $125 \mathrm{~V}$ and transferred to nitrocellulose membrane for $1 \mathrm{~h}$ at $30 \mathrm{~V}$. The membranes were blocked overnight with $\mathrm{PBST}+5 \%$ non-fat milk, incubated with plasma at 1:100 dilution for $2 \mathrm{~h}$ at room temperature and then at $4{ }^{\circ} \mathrm{C}$ overnight. The next day membranes were washed 4 times with PBST $+5 \%$ non-fat milk followed by incubation with anti-monkey-HRP conjugated IgG (Cappel, OH, USA, catalogue number 55432) secondary antibody at 1:500 in PBST $+5 \%$ non-fat milk, for $2 \mathrm{~h}$ at room temperature. After washing 3 times with PBST $+5 \%$ non-fat milk followed by a 20 min wash with PBST, the membrane proteins were visualized by chemiluminescence using SuperSignal WestPico Chemiluminescent Substrate (Pierce) and exposed on X-ray films.

\section{Conclusions}

The study showed that pre-existing, natural SFV infection significantly influenced the results of experimental SIV infection in the rhesus macaque model; there were increases in SIV plasma viral 
load, in loss of CD4+ T cells, and in animal deaths as compared to SFV negative animals. The results underscore the importance of SFV screening of monkeys used in SIV pathogenesis and AIDS vaccine studies. Further investigations of dual retrovirus expression in SFV/SIV co-infected animals will provide insight regarding virus-virus and virus-host dynamics and may elucidate the potential role of SFV in enhancing SIV infection and disease.

\section{Acknowledgments}

We thank the assistance of Ernest Madison, Shelly Lower, Lewis Shankle, and Brianna Skinner-Harris with animal bleeds and care, and David C. Montefiori for providing the SIV neutralizing antibody data. The study was initiated by funding from Biomedical Advanced Research and Development Authority (BARDA; previously ORDC/OPHEMC). The following reagent was obtained through the AIDS Research and Reference Reagent Program, Division of AIDS, NIAID, NIH: 174×CEM from Peter Cresswell. We are grateful to Ronald Desrosiers and Eliosa Yuste for the cloned SIV $_{\text {mac239 }}$ DNA, protocols for virus preparation, and to Ronald Desrosiers and Mark Lewis for discussions regarding the SIV study.

\section{Conflict of Interest}

The authors declare no conflict of interest.

\section{References and Notes}

1. Johnson, P.R.; Hirsch, V.M. SIV infection of macaques as a model for AIDS pathogenesis. Int. Rev. Immunol. 1992, 8, 55-63.

2. Murray, S.M.; Picker, L.J.; Axthelm, M.K.; Hudkins, K.; Alpers, C.E.; Linial, M.L. Replication in a superficial epithelial cell niche explains the lack of pathogenicity of primate foamy virus infections. J. Virol. 2008, 82, 5981-5985.

3. Falcone, V.; Leupold, J.; Clotten, J.; Urbanyi, E.; Herchenroder, O.; Spatz, W.; Volk, B.; Bohm, N.; Toniolo, A.; Neumann-Haefelin, D.; et al. Sites of simian foamy virus persistence in naturally infected African green monkeys: Latent provirus is ubiquitous, whereas viral replication is restricted to the oral mucosa. Virology 1999, 257, 7-14.

4. Switzer, W.M.; Salemi, M.; Shanmugam, V.; Gao, F.; Cong, M.E.; Kuiken, C.; Bhullar, V.; Beer, B.E.; Vallet, D.; Gautier-Hion, A.; et al. Ancient co-speciation of simian foamy viruses and primates. Nature 2005, 434, 376-380.

5. Liu, W.; Worobey, M.; Li, Y.; Keele, B.F.; Bibollet-Ruche, F.; Guo, Y.; Goepfert, P.A.; Santiago, M.L.; Ndjango, J.B.; Neel, C.; et al. Molecular ecology and natural history of simian foamy virus infection in wild-living chimpanzees. PLoS Pathog. 2008, 4, e1000097.

6. Yu, S.F.; Stone, J.; Linial, M.L. Productive persistent infection of hematopoietic cells by human foamy virus. J. Virol. 1996, 70, 1250-1254.

7. Saib, A.; Neves, M.; Giron, M.L.; Guillemin, M.C.; Valla, J.; Peries, J.; Canivet, M. Long-term persistent infection of domestic rabbits by the human foamy virus. Virology 1997, 228, 263-268. 
8. Swack, N.S.; Hsiung, G.D. Pathogenesis of simian foamy virus infection in natural and experimental hosts. Infect Immun. 1975, 12, 470-474.

9. Switzer, W.M.; Bhullar, V.; Shanmugam, V.; Cong, M.E.; Parekh, B.; Lerche, N.W.; Yee, J.L.; Ely, J.J.; Boneva, R.; Chapman, L.E.; et al. Frequent simian foamy virus infection in persons occupationally exposed to nonhuman primates. J. Virol. 2004, 78, 2780-2789.

10. Betsem, E.; Rua, R.; Tortevoye, P.; Froment, A.; Gessain, A. Frequent and recent human acquisition of simian foamy viruses through apes' bites in central Africa. PLoS Pathog. 2011, 7, e1002306.

11. Jones-Engel, L.; Engel, G.A.; Schillaci, M.A.; Rompis, A.; Putra, A.; Suaryana, K.G.; Fuentes, A.; Beer, B.; Hicks, S.; White, R.; et al. Primate-to-human retroviral transmission in Asia. Emerg. Infect. Dis. 2005, 11, 1028-1035.

12. Wolfe, N.D.; Switzer, W.M.; Carr, J.K.; Bhullar, V.B.; Shanmugam, V.; Tamoufe, U.; Prosser, A.T.; Torimiro, J.N.; Wright, A.; Mpoudi-Ngole, E.; et al. Naturally acquired simian retrovirus infections in central African hunters. Lancet 2004, 363, 932-937.

13. Khan, A.S. Simian foamy virus infection in humans: Prevalence and management. Expert Rev. Anti. Infect. Ther. 2009, 7, 569-580.

14. Gessain, A.; Rua, R.; Betsem, E.; Turpin, J.; Mahieux, R. HTLV-3/4 and simian foamy retroviruses in humans: Discovery, epidemiology, cross-species transmission and molecular virology. Virology 2013, 435, 187-199.

15. Boneva, R.S.; Switzer, W.M.; Spira, T.J.; Bhullar, V.B.; Shanmugam, V.; Cong, M.E.; Lam, L.; Heneine, W.; Folks, T.M.; Chapman, L.E. Clinical and virological characterization of persistent human infection with simian foamy viruses. AIDS Res. Hum. Retrovir. 2007, 23, 1330-1337.

16. Switzer, W.M.; Garcia, A.D.; Yang, C.; Wright, A.; Kalish, M.L.; Folks, T.M.; Heneine, W. Coinfection with HIV-1 and simian foamy virus in West Central Africans. J. Infect. Dis. 2008, 197, 1389-1393.

17. Murray, S.M.; Picker, L.J.; Axthelm, M.K.; Linial, M.L. Expanded tissue targets for foamy virus replication with simian immunodeficiency virus-induced immunosuppression. J. Virol. 2006, 80, 663-670.

18. Keller, A.; Garrett, E.D.; Cullen, B.R. The Bel-1 protein of human foamy virus activates human immunodeficiency virus type 1 gene expression via a novel DNA target site. J. Virol. 1992, 66, 3946-3949.

19. Marino, S.; Kretschmer, C.; Brandner, S.; Cavard, C.; Zider, A.; Briand, P.; Isenmann, S.; Wagner, E.F.; Aguzzi, A. Activation of HIV transcription by human foamy virus in transgenic mice. Lab. Invest. 1995, 73, 103-110.

20. Schiffer, C.; Lecellier, C.H.; Mannioui, A.; Felix, N.; Nelson, E.; Lehmann-Che, J.; Giron, M.L.; Gluckman, J.C.; Saib, A.; Canque, B. Persistent infection with primate foamy virus type 1 increases human immunodeficiency virus type 1 cell binding via a Bet-independent mechanism. J. Virol. 2004, 78, 11405-11410.

21. Giraldo-Vela, J.P.; Rudersdorf, R.; Chung, C.; Qi, Y.; Wallace, L.T.; Bimber, B.; Borchardt, G.J.; Fisk, D.L.; Glidden, C.E.; Loffredo, J.T.; et al. The major histocompatibility complex class II alleles Mamu-DRB1*1003 and -DRB1*0306 are enriched in a cohort of simian immunodeficiency virus-infected rhesus macaque elite controllers. J. Virol. 2008, 82, 859-870. 
22. Kaizu, M.; Borchardt, G.J.; Glidden, C.E.; Fisk, D.L.; Loffredo, J.T.; Watkins, D.I.; Rehrauer, W.M. Molecular typing of major histocompatibility complex class I alleles in the Indian rhesus macaque which restrict SIV CD8+ T cell epitopes. Immunogenetics 2007, 59, 693-703.

23. Regier, D.A.; Desrosiers, R.C. The complete nucleotide sequence of a pathogenic molecular clone of simian immunodeficiency virus. AIDS Res. Hum. Retrovir. 1990, 6, 1221-1231.

24. Dang, Q.; Hirsch, V.M. Rapid disease progression to AIDS due to Simian immunodeficiency virus infection of macaques: Host and viral factors. Adv. Pharmacol. 2008, 56, 369-398.

25. Montefiori, D.C. Measuring HIV neutralization in a luciferase reporter gene assay. Methods Mol. Biol. 2009, 485, 395-405.

26. Bontrop, R.E.; Watkins, D.I. MHC polymorphism: AIDS susceptibility in non-human primates. Trends Immunol. 2005, 26, 227-233.

27. Muhl, T.; Krawczak, M.; Ten Haaft, P.; Hunsmann, G.; Sauermann, U. MHC class I alleles influence set-point viral load and survival time in simian immunodeficiency virus-infected rhesus monkeys. J. Immunol. 2002, 169, 3438-3446.

28. Mothe, B.R.; Weinfurter, J.; Wang, C.; Rehrauer, W.; Wilson, N.; Allen, T.M.; Allison, D.B.; Watkins, D.I. Expression of the major histocompatibility complex class I molecule Mamu-A*01 is associated with control of simian immunodeficiency virus SIVmac239 replication. J. Virol. 2003, 77, 2736-2740.

29. Loffredo, J.T.; Maxwell, J.; Qi, Y.; Glidden, C.E.; Borchardt, G.J.; Soma, T.; Bean, A.T.; Beal, D.R.; Wilson, N.A.; Rehrauer, W.M.; et al. Mamu-B*08-positive macaques control simian immunodeficiency virus replication. J. Virol. 2007, 81, 8827-8832.

30. Yant, L.J.; Friedrich, T.C.; Johnson, R.C.; May, G.E.; Maness, N.J.; Enz, A.M.; Lifson, J.D.; O'Connor, D.H.; Carrington, M.; Watkins, D.I. The high-frequency major histocompatibility complex class I allele Mamu-B*17 is associated with control of simian immunodeficiency virus SIVmac239 replication. J. Virol. 2006, 80, 5074-5077.

31. Reed, J.S.; Sidney, J.; Piaskowski, S.M.; Glidden, C.E.; Leon, E.J.; Burwitz, B.J.; Kolar, H.L.; Eernisse, C.M.; Furlott, J.R.; Maness, N.J.; et al. The role of MHC class I allele Mamu-A*07 during SIV(mac)239 infection. Immunogenetics 2011, 63, 789-807.

32. Heberling, R.L.; Kalter, S.S. Rapid dot-immunobinding assay on nitrocellulose for viral antibodies. J. Clin. Microbiol. 1986, 23, 109-113.

33. Committee for the Update of the Guide for the Care and Use of Laboratory Animals; National Research Council. Guide for the Care and Use of Laboratory Animals; National Academy Press: Washington, DC, USA, 1996.

34. Khan, A.S.; Sears, J.F.; Muller, J.; Galvin, T.A.; Shahabuddin, M. Sensitive assays for isolation and detection of simian foamy retroviruses. J. Clin. Microbiol. 1999, 37, 2678-2686.

35. Newberg, M.H.; McEvers, K.J.; Gorgone, D.A.; Lifton, M.A.; Baumeister, S.H.; Veazey, R.S.; Schmitz, J.E.; Letvin, N.L. Immunodomination in the evolution of dominant epitope-specific CD8+ $\mathrm{T}$ lymphocyte responses in simian immunodeficiency virus-infected rhesus monkeys. J. Immunol. 2006, 176, 319-328.

36. Yuste, E.; Reeves, J.D.; Doms, R.W.; Desrosiers, R.C. Modulation of Env content in virions of simian immunodeficiency virus: Correlation with cell surface expression and virion infectivity. J. Virol. 2004, 78, 6775-6785. 
37. Karber, G.A. A contribution to the collective treatment of a pharmacological experimental series. Arch. Exp. Pathol. Pharmakol. 1931, 162, 480-483.

38. Salter, R.D.; Howell, D.N.; Cresswell, P. Genes regulating HLA class I antigen expression in T-B lymphoblast hybrids. Immunogenetics 1985, 21, 235-246.

39. Sodora, D.L.; Lee, F.; Dailey, P.J.; Marx, P.A. A genetic and viral load analysis of the simian immunodeficiency virus during the acute phase in macaques inoculated by the vaginal route. AIDS Res. Hum. Retrovir. 1998, 14, 171-181.

40. Dailey, P.J.; Zamroud, M.; Kelso, R.; Kolberg, J.; Urdea, M. Quantitation of Simian Immunodeficiency Virus (SIV) RNA in Plasma of Acute and Chronically Infected Rhesus Macaques Using a Branched DNA (bDNA) Signal Amplification Assay. In Proceedings of the 13th Annual Symposium Nonhuman Primate Models of AIDS, Monterey, CA, USA, 5-8 November 1995.

41. Yuste, E.; Sanford, H.B.; Carmody, J.; Bixby, J.; Little, S.; Zwick, M.B.; Greenough, T.; Burton, D.R.; Richman, D.D.; Desrosiers, R.C.; et al. Simian immunodeficiency virus engrafted with human immunodeficiency virus type 1 (HIV-1)-specific epitopes: Replication, neutralization, and survey of HIV-1-positive plasma. J. Virol. 2006, 80, 3030-3041.

(C) 2013 by the authors; licensee MDPI, Basel, Switzerland. This article is an open access article distributed under the terms and conditions of the Creative Commons Attribution license (http://creativecommons.org/licenses/by/3.0/). 